Stanford University

Twitter @AbraarKaran

Cite this as: $B M J 2022 ; 376: 085$ http://dx.doi.org/10.1136/bmj.085 Published: 12 January 2022

\section{What the face mask debacle can teach us about pandemic response}

Inconsistent messaging from US officials on the use of face masks has sowed public confusion and political divisiveness during the covid-19 pandemic, writes Abraar Karan

\section{Abraar Karan infectious disease doctor}

When face masks were first discouraged for public use by US public health officials at the start of the covid-19 pandemic, ${ }^{1}$ one of the arguments they presented was that they could lead to less physical distancing and thus more viral spread. Data from states that instituted mask mandates have since shown otherwise. ${ }^{2}$ And, recently, a randomised trial of community masking in Bangladesh showed the exact opposite ${ }^{3}$ : that the use of face masks actually increased physical distancing, possibly by reminding people through an easily identifiable visual cue that there was still an ongoing pandemic.

The delay to institute public masking in the US (and many other countries) likely cost many lives, especially early on in the pandemic, when the virus was spreading exponentially and we had no verified therapeutics or vaccines. At the time, the lack of sound data one way or the other on the effectiveness of public masking as a policy led to US officials assuming that there would be harm in recommending it. That assumption ultimately turned out to be false; public confusion and political divisiveness have been the result.

Now that we are faced with an even more transmissible variant of covid-19, we would all benefit from even better masks, ${ }^{4}$ such as N95s, to reduce transmission. Yet we are faced with rolling this out amid a climate in which masks have become regarded by some as a political prop more than a public health tool.

This debacle around community masking teaches us four important lessons for our pandemic response.

\section{Acknowledging uncertainty}

First, uncertainty must be communicated clearly and transparently. Assertively declaring at the start of the pandemic that masks were not needed, when in fact at the time officials were unsure whether they were needed, was a costly mistake. The later retraction of that initial stance sowed doubt within the public. A better alternative would have been to acknowledge that it was unclear how effective masks would be, that there was concern people would distance less or wear them incorrectly, ${ }^{5}$ and thus, to allow people to make informed decisions. This would have also left space for the revision of those recommendations.

\section{The precautionary principle}

Second, when there is uncertainty in an emergency, the precautionary principle should be invoked. That is to say, one must weigh the benefits and harms of doing interventions, and also the cost of not doing them. In some cases, the consequences of inaction could be catastrophic, as it was with SARS-CoV-2.
When it came to masks, officials should have assumed that the virus was airborne until proven otherwise. This would have translated into different recommendations for face masks, such as encouraging high filtration masks, as some doctors and scientists (including myself) had urged publicly as early as May 2020, ${ }^{6}$ unless it became clear that they weren't needed. As it turns out, the virus is airborne and high filtration masks are now being called for by many experts worldwide.

\section{Setting public expectations}

Third, managing public expectations must be central when rolling out an intervention during a health crisis. A key part of this is that risk must be presented as a continuum, not an absolute. Otherwise, interventions will also be judged as absolutes (i.e., masks work or masks don't work). Fundamentally, masks and other interventions can reduce risk but not eliminate it entirely. The same principle applies to vaccines. A case of someone infected with covid-19 while wearing a mask or after getting vaccinated is not evidence that masks or vaccines don't work. It's evidence that they work within their limitations (reducing, not eliminating, the risk of infection).

Similarly, part of setting expectations is establishing when certain interventions are no longer needed. In the US some commentators have been advocating for an end date for public masking; this was attempted by the US Centers for Disease Control and Prevention (CDC) last summer for those who were fully vaccinated, ${ }^{7}$ but it was too soon and had to be reversed within a couple of months, ${ }^{8}$ leading to even more confusion. Because of Omicron, this timeline, once again, will need to shift. The CDC is now even considering recommending higher filtration masks for all who can wear them correctly. ${ }^{9}$

\section{Prevention's invisible benefits}

Fourth, preventative interventions such as masks will have invisible benefits-and must be adequately framed as such. The challenge here is that for every instance that someone is infected, the public has a hard time appreciating the thousands for whom an infection was prevented..$^{10}$ You can't easily measure what you can't easily see. This differs from therapeutics, with which people can observe a tangible benefit. The success of prevention measures must be framed as the lack of a worse outcome; that message cannot be lost, or it will become hijacked as evidence that the intervention was not needed (when in fact it is evidence that it worked).

This past week, the director of the US CDC has been under fire for the organisation's lack of clear and frequent public communication. ${ }^{11}$ As I've outlined, 
the failings around masks alone can provide many key lessons on communication during a health crisis. Omicron is devastating the US's healthcare workforce quickly due to high infection rates ${ }^{12}$; there are early indicators that it is leading to more severe disease than was seen in South Africa ${ }^{13}$; and it is still leading to many hospitalisations among the unvaccinated. ${ }^{14}$ As the US and the world battles yet another variant of covid-19, public health officials must learn from these fundamental mishaps to help increase public buy-in and interrupt transmission quickly.

Competing interests: Abraar Karan had served as a paid research consultant to the Independent Panel on Pandemic Preparedness and Response in 2020.

Provenance and peer review: commissioned, not peer reviewed.

1 Fazio M. How Mask Guidelines Have Evolved. The New York Times. 27 April 2021.

2 Lyu W, Wehby GL. Community Use Of Face Masks And COVID-19: Evidence From A Natural Experiment Of State Mandates In The US. Health Aff (Millwood) 2020;39:1419-25. doi: 10.1377/hlthaff.2020.00818. pmid: 32543923

3 Abaluck J, Kwong LH, Styczynski A, etal. Impact of community masking on COVID-19: A cluster-randomized trial in Bangladesh. Science 2021;2:eabi9069. doi: 10.1126/science.abi9069. pmid: 34855513

4 Dhillon RS, Karan A, Beier D, Srikrishna D. We Need Better Masks. Harv Bus Rev. 18 June 2020 https://hbr.org/2020/06/we-need-better-masks.

5 Howard J. Masks may actually increase your coronavirus risk if worn improperly, surgeon general warns. CNN Health. 2 March 2020. https://edition.cnn.com/2020/03/02/health/surgeon-generalcoronavirus-masks-risk-trnd/index.html

6 Dhillon RS, Karan A, Beier D, etal. A Plan to Safely Reopen the U.S. Despite Inadequate Testing. Harv Bus Rev. 1 May 2020. https://hbr.org/2020/05/a-plan-to-safely-reopen-the-u-s-despiteinadequate-testing.

7 Abutaleb Y, McGinley L. CDC says fully vaccinated Americans no longer need masks indoors or outdoors in many cases. Washington Post. 13 May 2021. https://www. washingtonpost.com/health/2021/05/13/cdc-says-fully-vaccinated-americans-no-longer-need-masks-indoorsor-outdoors-most-cases/

8 Lovelace B Jr. CDC reverses indoor mask policy, saying fully vaccinated people and kids should wear them indoors. CNBC. 27 July 2021. https://www.cnbc.com/2021/07/27/cdc-to-reverse-indoormask-policy-to-recommend-them-for-fully-vaccinated-people-in-covid-hot-spots.html

9 Sun LH, Roubein R. CDC weighs recommending better masks against omicron variant. Washington Post. 10 January 2022. https://www.washingtonpost.com/health/2022/01/10/cdc-weighs-n95kn95-masks-guidance-omicron/

10 Karan A. The thankless task of social distancing. Vox. 19 March 2020 https://www.vox.com/2020/3/19/21186750/coronavirus-covid-19-social-distancing-stayinghome-saving-lives

11 Simmons-Duffin S. CDC is criticized for failing to communicate, promises to do better. NPR. 7 January 2022. https://www.npr.org/sections/health-shots/2022/01/07/1071449137/cdc-is-criticized-for-failing-to-communicate-promises-to-do-better?t=1641903912779

12 Alpert Reyes ELA. healthcare system hit with widening staffing shortages as workers get coronavirus. Los Angeles Times. 5 January 2022. https://www.latimes.com/california/story/202201-05/healthcare-workers-covid-surge-infections

13 Wallace-Wells D. America's Omicron Wave Already Looks More Severe Than Europe's. Intelligencer. 7 January 2022. https://nymag.com/intelligencer/2022/01/americas-omicron-wavenow-looks-more-severe-than-europes.html

14 Caldwell T. States are scrambling to keep up with an increase in Covid-19 hospitalizations and the demand for testing. CNN Health. 9 January 2022. https://edi-

tion.cnn.com/2022/01/08/health/us-coronavirus-saturday/index.html 